\title{
Closed chest transthoracic perventricular ventricular septal defect closure under real-time MRI
}

\author{
Kanishka Ratnayaka*1, Christina E Saikus ${ }^{1}$, Anthony Z Faranesh ${ }^{1}$, \\ Merdim Sonmez ${ }^{1}$, Israel Barbash ${ }^{1}$, Venkatesh K Raman ${ }^{1}$, Ozgur Kocaturk ${ }^{1}$, \\ Michael C Slack ${ }^{2}$ and Robert J Lederman ${ }^{1}$
}

Address: ${ }^{1}$ National Heart, Lung, and Blood Institute/NIH, Bethesda, MD, USA and ${ }^{2}$ Children's National Medical Center, Washington, DC, USA

* Corresponding author

from 13th Annual SCMR Scientific Sessions

Phoenix, AZ, USA. 2I-24 January 2010

Published: 21 January 2010

Journal of Cardiovascular Magnetic Resonance 2010, I2(Suppl I):O24 doi:I0.1 I86/I532-429X-I2-SI-O24

This abstract is available from: http://jcmr-online.com/content/I2/SI/O24

(C) 2010 Ratnayaka et al; licensee BioMed Central Ltd.

\section{Introduction}

Muscular ventricular septal defect (VSD) is common, and can be congenital, post-infarction, or post-traumatic. Real-time MRI can provide surgical-grade exposure for non-surgical procedures. One innovative pediatric surgical procedure is device closure of ventricular septal defect using catheter techniques through an open chest. We attempt to conduct this same procedure in a closed chest model using real-time MRI.

\section{Purpose}

We hypothesize real-time MRI could guide closed chest transthoracic perventricular VSD device closure on beating hearts in swine without cardiopulmonary bypass or thoracotomy.

\section{Methods}

We developed a novel closed chest transcatheter model of muscular VSD in naïve Yorkshire swine using X-Ray Fused with MRI and excimer laser ablation. For real-time MRI guided closure, ECG gated segmented steady state free precession roadmaps identified optimal transthoracic, perventricular needle trajectory to engage VSD. Real-time MRI guided needle puncture of the chest wall and then of the right ventricular free wall. Next the septal defect was crossed using real-time MRI guidance, and a nitinol VSD closure device (AGA Medical) deployed [Figure 1].
Finally, the right ventricular free wall was closed using catheter techniques.

\section{Results}

Real-time cardiac MRI permitted transthoracic perventricular VSD device closure and then free wall repair. There were no procedural complications including conduction or rhythm abnormalities, atrioventricular or semilunar valvular regurgitation, or device embolization. Small procedural effusions were drained with temporary pericardial catheters. Necropsy confirmed optimal device placement.

\section{Conclusion}

Transthoracic MRI guided perventricular muscular VSD closure is feasible in a porcine model, and has the potential to avoid cardiopulmonary bypass (traditional VSD surgical repair) or even sternotomy (hybrid perventricular approach). It is a radiation sparing alternative for small children in whom percutaneous options are risky or not possible. 

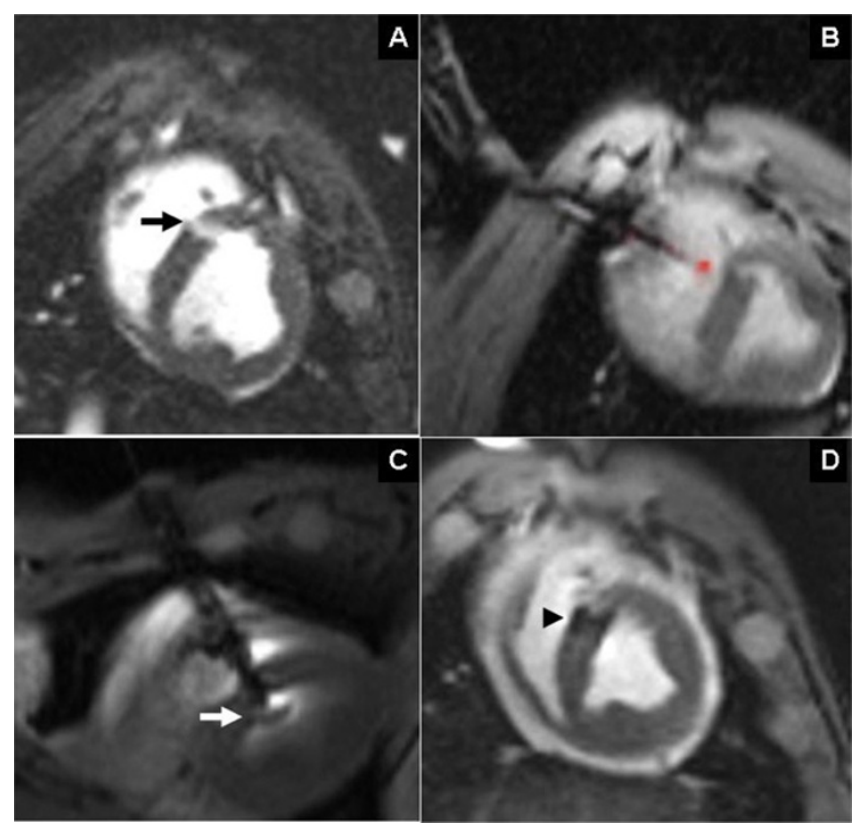

\section{Figure I}

Closed chest transthoracic perventricular ventricular septal defect closure under real-time MRI. Panel A shows muscular ventricular septal defect (thick, black arrow) highlighted by steady state free precession (SSFP) imaging. In pre-determined optimal imaging planes, "active" needle (red with needle tip appearing as bright red spot) puncture of the right thoraz and subsequently the right ventricular free wall is shown in panel B. Panel C shows ventricular septal defect closure device (thick, white arrow) with left ventricular disk deployed. Panel D shows succesful device implantation (black arrowhead).

Publish with Bio Med Central and every scientist can read your work free of charge

"BioMed Central will be the most significant development for disseminating the results of biomedical research in our lifetime. "

Sir Paul Nurse, Cancer Research UK

Your research papers will be:

- available free of charge to the entire biomedical community

- peer reviewed and published immediately upon acceptance

- cited in PubMed and archived on PubMed Central

- yours - you keep the copyright
BioMedcentral 